\title{
PRIMARY TRANSITIONAL CELL CARCINOMA OF THE OVARY: A CASE REPORT
}

Anju Singh', Mona Lisa ${ }^{2}$, Ravi Bhushan Raman ${ }^{3}$, Zeenat S. Imam ${ }^{4}$, Suryajit Kumar Singh ${ }^{5}$

${ }^{1}$ Associate Professor, Department of Pathology, Indira Gandhi Institute of Medical Sciences, Patna. ${ }^{2}$ Senior Resident, Department of Pathology, Indira Gandhi Institute of Medical Sciences, Patna. ${ }^{3}$ Senior Resident, Department of Pathology, Indira Gandhi Institute of Medical Sciences, Patna. ${ }^{4}$ Senior Resident, Department of Pathology, Indira Gandhi Institute of Medical Sciences, Patna. ${ }^{5}$ Senior Resident, Department of Pathology, Indira Gandhi Institute of Medical Sciences, Patna.

\section{ABSTRACT}

A 38-year-old female presented with a history of progressively enlarging abdominal mass. Abdominal computed tomography showed a pelvic mass involving both the ovaries and omentum. CA-125 was normal. Staging surgery was performed and the histopathological diagnosis of Transitional Cell Carcinoma was made and later confirmed by immuno-histochemistry. Transitional cell carcinoma of the ovary is a rare subtype of epithelial ovarian cancer. Surgical resection is the primary therapeutic approach, and patient's outcomes after chemotherapy are better than for other types of ovarian cancers.

\section{KEYWORDS}

Transitional Cell Carcinoma, Ovary.

HOW TO CITE THIS ARTICLE: Singh A, Lisa M, Raman RB, et al. Primary transitional cell carcinoma of the ovary: a case report. J. Evolution Med. Dent. Sci. 2016;5(39):2411-2412, DOI: 10.14260/jemds/2016/561

\section{INTRODUCTION}

Transitional Cell Carcinoma (TCC) is usually a cancer of the urothelial tract. Ovary is a rare site for such a tumour. The pure form of TCC accounts for only $1 \%$ of surface epithelial tumours of ovary. ${ }^{1}$ It is important to recognise such a rare tumour, because it has a better response to chemotherapy and patient outcome.

\section{Case Presentation}

A 38-year-old woman presented with a one-year history of abdominal lump and pain. She had lost about $4 \mathrm{~kg}$ weight during the 6 months prior to admission. Physical examination showed a pelvic mass. Abdominal Computed Tomography (CT) showed a large solid cystic mass extending from umbilicus to pelvis. Bilateral ovaries could not be seen separately. The right-sided mass measured $16.2 \times 10.9$ and the left-sided mass was $12 \times 6 \mathrm{~cm}$. There was no enlargement of the para-aortic lymph node and the liver and kidneys were unremarkable. Routine biologic test results were all within normal ranges. CA-125 level before surgery was within normal limits. The surgery was done considering a malignant ovarian tumour and the specimen consisted grossly of 2 solid/cystic masses $14 \times 10 \times 5$ and $7 \times 6 \times 4$, arising from the right and left ovary respectively. The omentum also showed a tumour nodule measuring $8 \times 7 \times 5 \mathrm{~cm}$ (Fig. 1). Therefore, surgical staging procedures including total abdominal hysterectomy, bilateral salpingo-oophorectomy, infracolic omentectomy and pelvic lymph node dissection were performed. Microscopic examination of $\mathrm{H}$ and $\mathrm{E}$ stained slides showed malignant transitional epithelial lining of the ovarian cysts with an undulating diffuse pattern. Mitosis was not infrequent and areas of necrosis were also seen (Fig. 2).

Financial or Other, Competing Interest: None.

Submission 30-03-2016, Peer Review 27-04-2016,

Acceptance 02-05-2016, Published 16-05-2016.

Corresponding Author:

Dr. Mona Lisa,

\#401 D, Ashirwad Enclave,

Anandpuri,

Patna-800001.

E-mail:monaloud@gmail.com

DOI: 10.14260/jemds/2016/561
The omental nodule and the pelvic lymph nodes also showed metastatic TCC. The final diagnosis was TCC, ovary grade III, stage II B (FIGO). Immunohistochemical studies showed that the tumour was positive for CA-125 (Figure 3), cytokeratin 7 and negative for CK20. The patient was referred to higher centre for post-operative chemotherapy and further management.

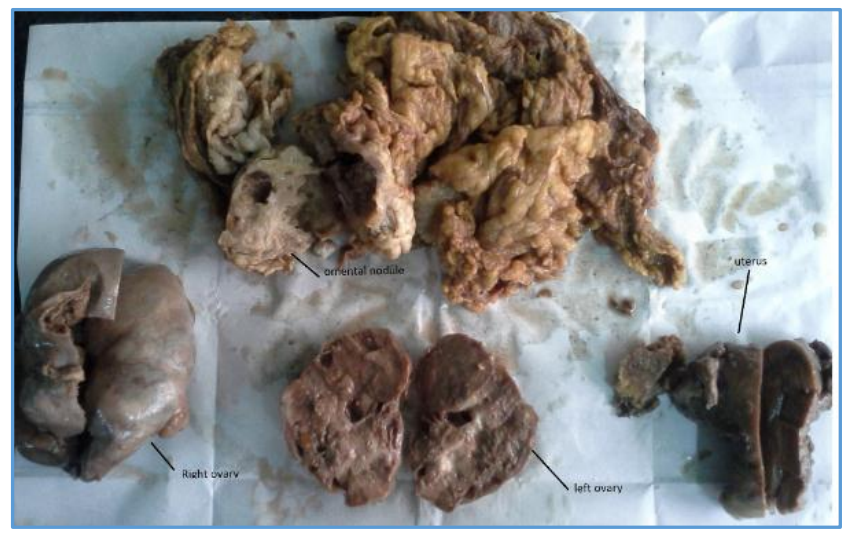

Fig. 1: Gross Image

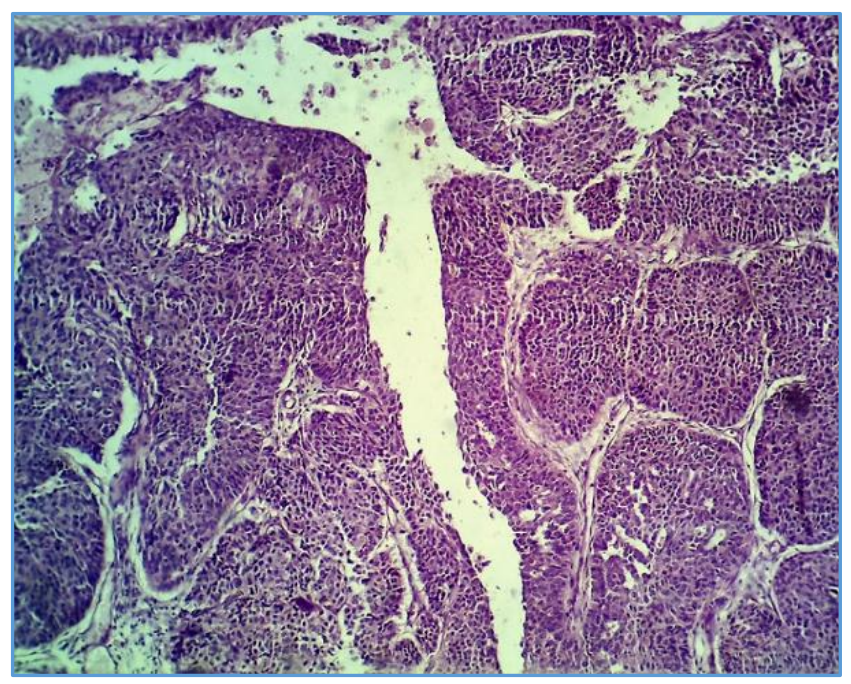

Fig. 2: H\&E Stained Image of Tumour 


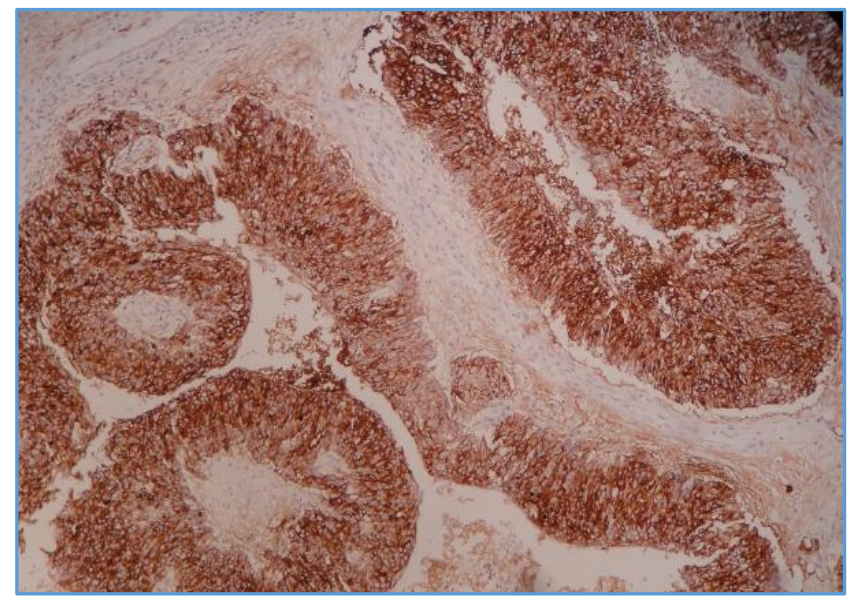

Fig. 3: CA-125 Positive Tumour

\section{DISCUSSION}

TCC of the ovary is defined as ovarian tumours presenting with histologic features similar to those seen in a malignant Brenner tumour, but lacking the associated benign Brenner tumour component. ${ }^{1}$ Ovarian TCC arises directly from the pluripotent surface epithelium of the ovary and from cells with urothelial potential, rather than from a benign or proliferative Brenner tumour precursor. ${ }^{1}$ In a study by Silva et al, focal or diffuse TCC pattern was seen in 88 of 934 ovarian cancers. ${ }^{2}$ They concluded that the pure form of TCC accounts for only $1 \%$ of surface epithelial tumours, mixed carcinomas with a minor TCC component comprise 3\% and those with a predominant TCC component make up 5\%. ${ }^{2}$

According to another observation, ovarian TCC typically showed undulating, diffuse, insular and trabecular growth patterns. ${ }^{3}$ The tumour cell nuclei are oblong or round, often exhibiting nucleoli or longitudinal grooves. The cytoplasm is often pale and granular, rarely clear or eosinophilic. Also, poorly differentiated serous cystadenocarcinomas often mimic high-grade transitional cell carcinoma. But they have a greater tendency to grow in diffuse masses; when they have a pattern simulating that of papillary TCCs. It is much more often caused by the presence of pseudopapillae resulting from necrosis with dropout of necrotic cellular debris.

TCCs have broad papillae lined by cells, some of which are recognizable as transitional cells; similar cells form undulating, thick bands. Scattered microspaces, which are often numerous also favour a diagnosis of TCC. ${ }^{3}$
The immunophenotype of TCC of the ovary is similar to that of other surface carcinomas of the ovary, but differs from that of TCC of the bladder. ${ }^{2}$ In addition, ovarian TCCs are negative for CK20, Thrombomodulin (TM) and uroplakin III, which are the antigens that are usually (CK20) or sometimes (TM and uroplakin III) detected in bladder TCCs. Unlike bladder TCCs, ovarian TCCs are often positive for vimentin, CA-125 and Wilms Tumour protein (WT1). ${ }^{3}$ Ovarian TCCs also mark strongly for Oestrogen Receptors (ERs), a characteristic that may help to differentiate these lesions from papillary urothelial carcinoma metastatic to the ovary. ${ }^{4}$ TCC of the ovary is reported to be sensitive to cisplatin-based chemotherapy and advanced-stage ovarian TCC is significantly more chemosensitive and associated with better prognosis than poorly differentiated serous carcinoma.2,5 Thus, it is important to recognise this type of cancer in a patient of ovarian tumour.

\section{CONCLUSION}

Transitional Cell Carcinoma (TCC) of the ovary is a rare subtype of epithelial ovarian cancer. Surgical resection is the primary therapeutic approach, and patient outcomes after chemotherapy are better than for other types of ovarian cancers.

\section{REFERENCES}

1. Austin RM, Norris HJ. Malignant brenner tumour and transitional cell carcinoma of the ovary: a comparison. Int J Gynaecol Pathol 1987;6(1):29-39.

2. Silva EG, Robey-Cafferty SS, Smith TL, et al. Ovarian carcinomas with transitional cell carcinoma pattern. Am J Clin Pathol 1990;93(4):457-65.

3. Eichhorn JH, Young RH. Transitional cell carcinoma of the ovary: a morphologic study of 100 cases with emphasis on differential diagnosis. Am J Surg Pathol 2004;28(4):453-63.

4. Croft PR, Lathrop SL, Feddersen RM, et al. Oestrogen receptor expression in papillary urothelial carcinoma of the bladder and ovarian transitional cell carcinoma. Arch Pathol Lab Med 2005;129(2):194-9.

5. Gershenson DM, Silva EG, Mitchell MF, et al. Transitional cell carcinoma of the ovary: a matched control study of advanced-stage patients treated with cisplatin based chemotherapy. Am J Obstet Gynaecol 1993;168(4):1178-85. 